\title{
THE INFLUENCE OF SOLUTION ANNEALING ON MICROSTRUCTURE AND MECHANICAL PROPERTIES OF HEAT- RESISTANT CAST STEEL HK30 MODIFIED BY NIOBIUM
}

\author{
Alen Delić ${ }^{1 *}$, Mirsada Oruč², Milenko Rimac ${ }^{2}$, Almaida Gigović-Gekić2 \\ Raza Sunulahpašić ${ }^{2}$ \\ ${ }^{1}$ TTU energetik d.o.o., 75000 Tuzla, Bosnia and Herzegovina \\ ${ }^{2}$ University of Zenica, 72000 Zenica, Bosnia and Herzegovina
}

Received 14.06.2019

Accepted 25.09.2019

\begin{abstract}
In this paper, the room temperature mechanical properties, as well as the microstructure of $\mathrm{HK} 30 \mathrm{Nb}$ steel, were tested in the initial as-cast and solution annealed condition. Results show that tensile properties after the solution annealing have a slightly lower value than as-cast samples. Microstructural analysis of samples after solution annealing showed dissolution of primary carbides present in the initial as-cast condition. The morphology and composition of carbides were changed during a solution annealing. Analysis of microstructure was done by optical microscopy (OM) and scanning electron microscope (SEM), whereas hardness and tensile tests were performed for characterization of mechanical properties.
\end{abstract}

Keywords: heat-resistant cast steel; solution annealing; mechanical properties; carbide.

\section{Introduction}

Stainless steels are distinguished from other steels by the enhanced corrosion and oxidation resistance created by chromium additions. Chromium imparts passivity to ferrous alloys when present in amounts higher than about $10.5 \mathrm{wt} . \%$, particularly if conditions are strongly oxidizing. Consequently, steels with higher than 10.5 or $12 \mathrm{wt} . \%$ $\mathrm{Cr}$ are sometimes defined as stainless steels. This article reviews the properties of cast steels specified either for application in aqueous environments below $650{ }^{\circ} \mathrm{C}$ or for service at temperatures above $650{ }^{\circ} \mathrm{C}$. The cast steels suitable for these applications are often high-alloy compositions because carbon and low-alloy steels do not provide sufficient corrosion resistance and/or strength at elevated temperatures. These high-alloy cast steels generally have higher than $10.5 \mathrm{wt}$. \% Cr. The usual difference between heat-

*Corresponding author: Alen Delić, alen.delic@ttuenergetik.ba 
resistant and corrosion-resistant cast steels is based on carbon content. H-Type (HeatResistant) steel castings are classified as heat resistant if they are capable of sustaining operation while exposed, either continuously or intermittently, to operating in excess of $650{ }^{\circ} \mathrm{C}$. Heat-resistant steel castings are similar to high-alloy corrosion-resistant steels except for their higher carbon content, which enables higher strength at elevated temperature, [1].

As typically produced, the HK alloy type is a stable austenitic over its entire temperature range of application. The as-cast microstructure consists of an austenite matrix containing massive carbides as scattered islands or networks. After aging at service temperature, the alloy exhibits a dispersion of fine, granular carbides within the austenite grains, with subsequent agglomeration if the temperature is high enough, [2].

Compared to the first generation of cast steel, annealing of HK steel with the same carbon content produces both increase of carbon and carbon fraction as well as increase of carbide size in eutectic. Additions of niobium and titanium introduced to cast steel give rise to the formation of straight and complex simple carbides. In each of these cases, simple carbides are characterised by different morphologies. The process of annealing changes in a significant way the phase composition and morphology of the precipitates. In the first generation of cast HK steel, the secondary chromium carbides of the $\mathrm{M}_{23} \mathrm{C}_{6}$ type start to precipitate. Their content in microstructure is a function of the annealing time and temperature and content of carbon and chromium [3].

Solution annealing is a heat treatment mostly used for austenitic stainless steels, before their exploitation. The main aim of this treatment, as the name implies, is to dissolve the phases precipitated during the thermomechanical processing as $\mathrm{M}_{23} \mathrm{C}_{6}$ - type carbide, where $\mathrm{M}=\mathrm{Cr}, \mathrm{Fe}$, Mo [4].

In the same time, the solution annealing prevents alloy to sensitization. The treatment consists of holding time at high temperatures in the range of 1040 to $1205{ }^{\circ} \mathrm{C}$ in order to dissolve the carbides, followed by fast cooling toprevent carbides reprecipitation [5]. This is possible due to the increase of carbon solubility in austenite as a consequence of the elevated temperatures. Another important consideration is that carbon carbides will always be present to some extent in the microstructure of alloys with carbon contents higher than $0.20 \mathrm{wt} \%$, such as HK30 alloy, regardless of the solution annealing treatment applied, [5].

The objective of this paper was to evaluate the effect of the annealing temperature on the microstructure, hardness and tensile properties of cast $\mathrm{HK} 30 \mathrm{Nb}$ heat resistant steel. Also, the aim was to compare mechanical properties of as-cast and thermally treated samples.

\section{Experimental}

\section{Procedure and material}

The subject of research in this paper is the heat resistant austenitic steel HK 30 according to ASTM A $351 \mathrm{M}$ standard modified by niobium (HK $30 \mathrm{Nb}$ ), centrifugally cast, which is used for production turbine engine parts for trucks.

From Table 1 it is noted that the chemical composition of the experimental cast HK $30 \mathrm{Nb}$ with the achieved values is by the standard ASME SA-351 (UNS J93400), [6]. The content of the chemical elements is within the limits of the prescribed values. 
Solution annealing process was carried out at a temperature of $1125{ }^{\circ} \mathrm{C}$, with a holding of $145 \mathrm{~min}$ with relatively slow cooling from the electro-resistant furnace to $700{ }^{\circ} \mathrm{C}$.

Table 1. Chemical composition of austenitic stainless-steel HK 30 per standard ASME SA-351 (UNS J93400) and experimental cast HK $30 \mathrm{Nb}$.

\begin{tabular}{|c|c|c|c|c|c|c|c|c|}
\hline \multirow{2}{*}{ Standards } & \multicolumn{8}{|c|}{ Composition, wt. \% } \\
\hline & $\mathrm{C}$ & $\mathrm{Cr}$ & $\mathrm{Ni}$ & $\mathrm{Si}$ & $\mathrm{Mn}$ & $\mathrm{P}$ & $S$ & $\mathrm{Nb}$ \\
\hline $\begin{array}{l}\text { ASME SA- } \\
351 \text { (UNS } \\
\text { J93400) }\end{array}$ & $\begin{array}{l}0.25- \\
0.35\end{array}$ & $\begin{array}{l}24.0- \\
27.0\end{array}$ & $\begin{array}{l}19.00- \\
22.0\end{array}$ & $\begin{array}{l}0.75- \\
1.30\end{array}$ & $\begin{array}{c}\max . \\
1.50\end{array}$ & $\begin{array}{l}\max . \\
0.04\end{array}$ & $\begin{array}{l}\max . \\
0.04\end{array}$ & $\begin{array}{l}1.00- \\
1.75\end{array}$ \\
\hline $\begin{array}{l}\text { Cast HK } 30 \\
\mathrm{Nb}\end{array}$ & 0.31 & 24.3 & 20.6 & 1.20 & 0.33 & 0.02 & 0.02 & 1.40 \\
\hline
\end{tabular}

Methods and techniques of characterization

The microhardness was determined by the Vickers method, applying a load of $1 \mathrm{~kg}$. Hardness was measured at the cross-section along the line as shown schematically in Fig. 1. The same procedure was applied to both as-cast and annealed samples.

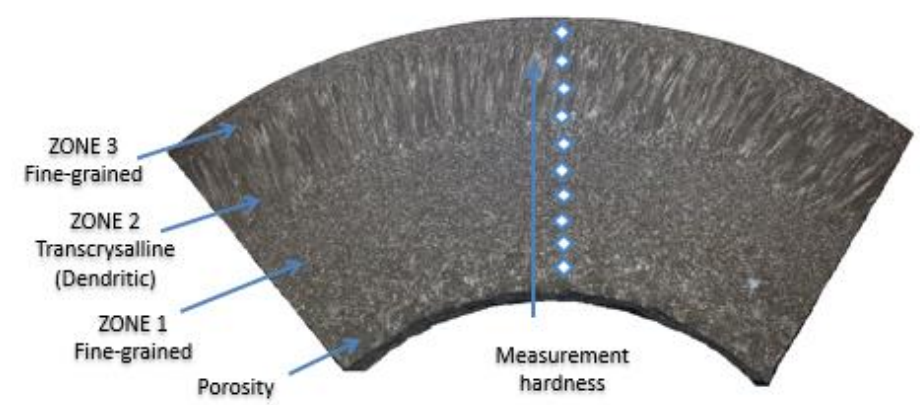

Fig. 1. The cross-section of the casting segment with designated zones in the structure and locations where the hardness was measured (the marked direction).

Tensile properties were investigated by using a universal testing machine Amsler with a deformation rate of $40 \mathrm{MPa} / \mathrm{s}$. Testing was performed in a cast and solution annealed condition on longitudinal tubes at a temperature of $20^{\circ} \mathrm{C}$. For each test, two test tubes were tested on samples by the standard BAS EN ISO 6892-2: 2012, Annex D [7].

Disposition of the samples in the 3D format is shown in Fig. 2. Testing of tensile properties of samples in as-cast and solution annealed condition, taken from two macrostructural zones, dendritic (trans-crystalline) and fine-grained (globular), was performed at room temperature. 


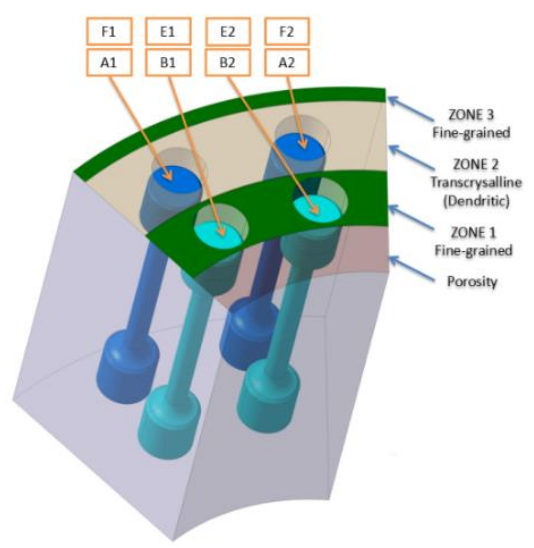

Fig. 2. A schematic presentation of the sampling for testing of the tensile properties in the longitudinal direction A1, A2, B1, and B2, of as-cast samples, and E1, E2, F1 and F2 samples in solution annealed condition.

Samples for microsstructural examination were prepared by standard metallographic techniques and etched with $\mathrm{C} 13$ reagent (composition: 20ml of hydrochloric acid $+4 \mathrm{~g}$ of copper sulfate $+20 \mathrm{ml}$ of distilled water). Morphology and distribution of individual microconstituents were determined using optical microscope (OM) Olympus DP-4 and Carl Zeiss Axio Imager M2M. Examination of the microstructure in as-cast and annealed condition was performed by the scanning electron microscope (SEM), JEOL JSM 6460 LV, equipped with the EDS (Energy Dispersive xray Spectroscopy) system INCA Oxford Instruments (Faculty of Technical Sciences, University of Novi Sad).

\section{Results and discussion}

Hardness and tensile properties

According to hardness results from Fig. 3, it can be concluded that the hardness values are relatively uniform in both the as-cast and the solution annealed condition. Generally, solution annealing produces a somewhat lower hardness value, which can be explained by the partial transition of coarse primary carbides into a solid austenite solution or by decomposition of primarily formed carbides.

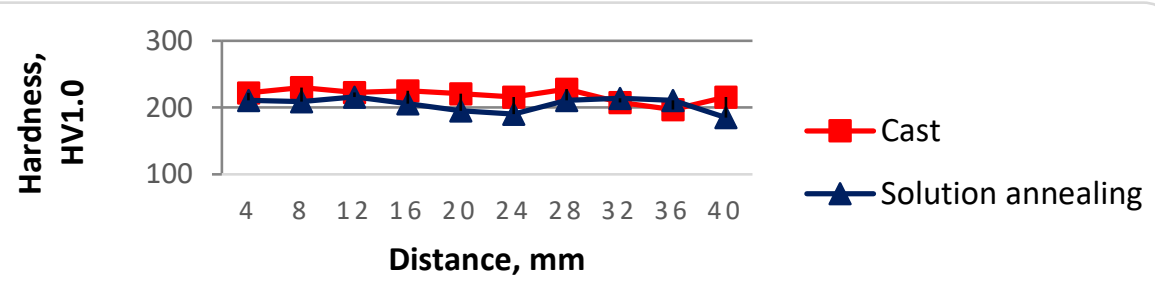

Fig.3. Cross-sectional HVI hardness distribution of as-cast sample and sample solution annealing 
Tensile tests of solution annealing conditions were performed only on samples in the longitudinal direction marked with E1, E2 (trans-crystalline zone) and F1, F2 (finegrained zone), see Fig. 2. All test results illustrated in Table 2, are compared with the values corresponding to ASTM A 351 and IDM 8365 standards $[8,9]$.

Table 2. Tensile properties of samples in as-cast and solution annealed state condition in a trans-crystalline and grain zone at room temperature.

\begin{tabular}{|c|c|c|c|c|c|}
\hline Standard / Mark & $\begin{array}{l}\text { Zone in the } \\
\text { structure }\end{array}$ & $\mathrm{R}_{\mathrm{p} 0.2}, \mathrm{MPa}$ & $\mathrm{R}_{\mathrm{m}}, \mathrm{MPa}$ & A, $\%$ & Sample \\
\hline A 351 as-cast & & $\min .240$ & $\min .450$ & $\min .10$ & \\
\hline $\begin{array}{l}\text { IDM } 8365 \\
\text { annealed }\end{array}$ & & $\min .240$ & $\min .450$ & $\min .10$ & \\
\hline HK 30 as-cast & $\begin{array}{l}\text { Trans- } \\
\text { crystalline }\end{array}$ & 308.5 & 594.0 & 17.5 & A1 A2 \\
\hline HK 30 as-cast & Fine-grained & 321.5 & 524.0 & 7.0 & B1 B2 \\
\hline HK 30 annealed & $\begin{array}{l}\text { Trans- } \\
\text { crystalline }\end{array}$ & 317.5 & 531.5 & 4.0 & E1 E2 \\
\hline HK 30 annealed & Fine-grained & 294.5 & 579.0 & 14.0 & F1 F2 \\
\hline HK 30 annealed & Fine-grained & 281.0 & 528.0 & 18.0 & EXOVA \\
\hline
\end{tabular}

The results of the examination were graphically presented in the histograms in Fig. 4. The histograms included the mean values of the room temperature test results of tensile properties in the as-cast and solution annealed condition compared with the results of corresponding standards and the tests carried out in the laboratory of the EXOVA Institute, the Czech Republic.

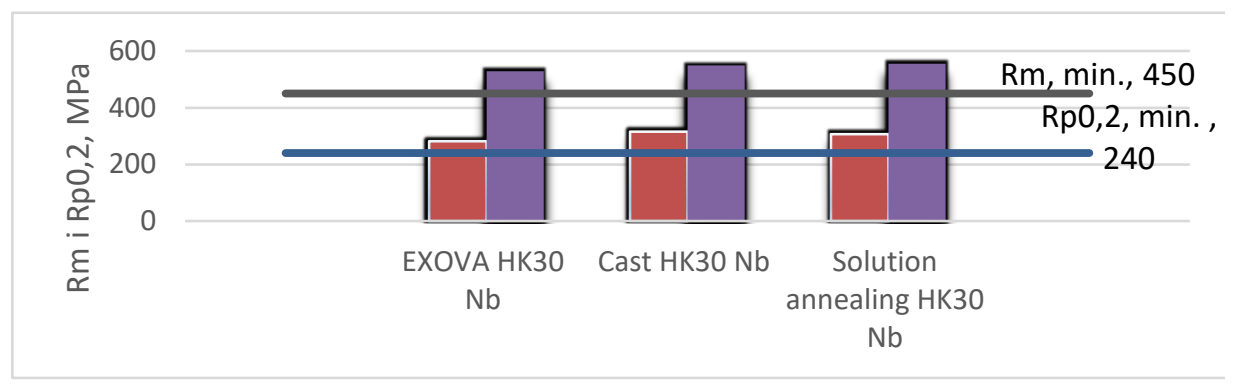

Fig.4. Tensile strength of as-cast and solution annealed samples compared with results of EXOVA Institute.

These results indicate that values of strength in this work are higher than those prescribed by standards, and the same applies to the results of EXOVA Institute. Also, according to presented results, the influence of solution annealing seems negligible on the strength of as-cast samples. Results from Table 2 clearly show that values of elongation of fine-grained as-cast and trans-crystalline annealed samples are lower than then standard values. On the other hand, samples of trans-crystalline as-cast and finegrained annealed samples have higher value of elongation compared to standard values. 


\section{Microstructural examination}

There is a significant difference in the microstructure of cast austenitic stainless steels compared to the wrought austenitic structure. There is usually a small amount of delta ferrite present in austenitic stainless-steel castings, in contrast to the single-phase austenitic structure of the wrought alloys. In this work, very extensive microstructure tests were performed applying by optical and scanning electron microscope in order to clarify the mechanisms occurring in the microstructure and leading to the change of properties.

Fig 5 (a) shows the OM microstructure of the as-cast sample. The microstructure consists of an austenitic matrix in which relatively large carbides are arranged along the boundaries of the primary grains and in the form of islands distributed in an austenitic matrix. In order to eliminate the unfavorable trans-crystalline carbide network, heat treatments with solution annealing are applied, to improve ductility, creep resistance and corrosion resistance. Fig. 5 (b) shows the structure after solution annealing. In comparison with the as-cast microstructure, a somewhat finer grain is observed and the dissolution of carbides along the austenitic grain boundaries. Unlike the as-cast structure on the boundary of primary austenitic grains, a large number of tiny carbides are present, which can be the result of the dissolution of massive carbides on the boundary and carbide islands inside the grain, as is indicated in some literature data [5].
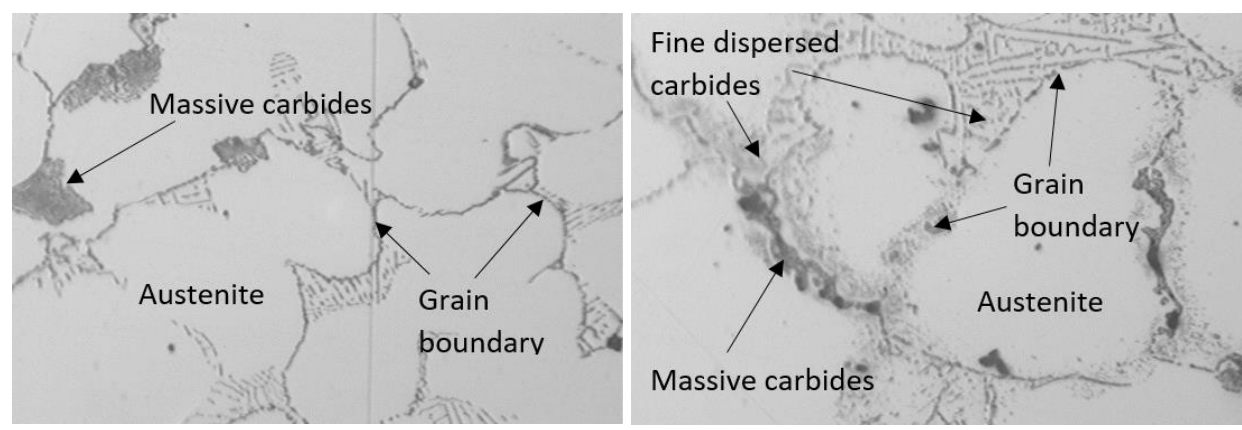

Fig. 5. The microstructure of the a) as-cast sample and b) sample after solution annealing (OM, x500).

SEM analysis of the as-cast sample microstructure is shown in Fig. 6 and Table 3; whereas Fig. 7 and Table 4 illustrate the SEM microstructure analysis of the same sample after solution annealing [10]. Identical tests were performed on the samples to distinguish the difference between these two microstructures. 


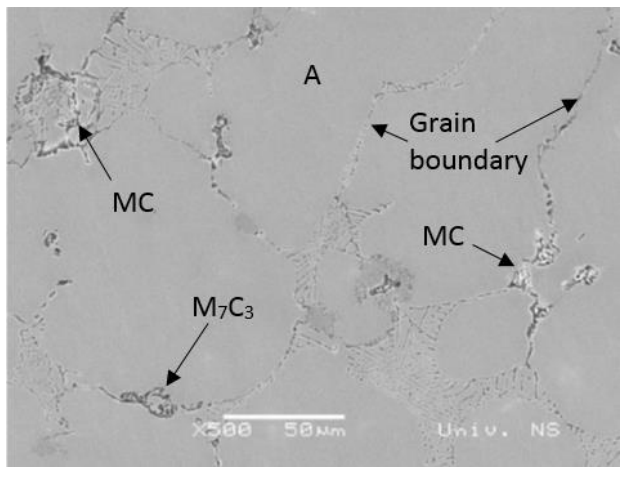

a.

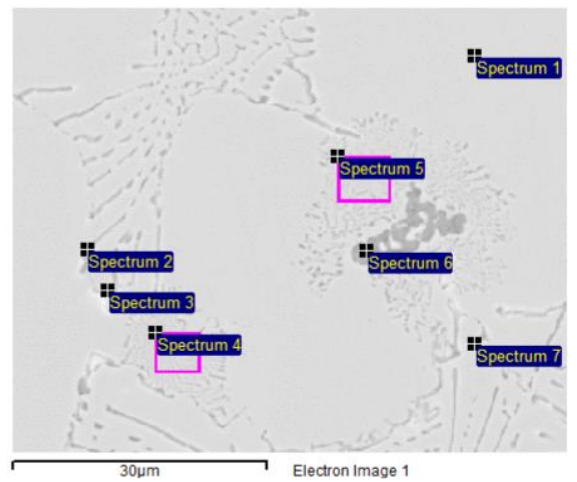

$b$.

Fig. 6. SEM analysis of the microstructure of the as-cast sample (a) at low magnification; (b) at higher magnification with marked positions for quantitative EDS analysis(b).

Table 3. Quantitative EDS analysis of the as-cast sample, at the locations, indicated in Fig. 6.b.

\begin{tabular}{lccccccc}
\hline \multirow{2}{*}{ Spectrum } & \multicolumn{7}{c}{ Composition,wt.\% } \\
& $\mathrm{C}$ & $\mathrm{Cr}$ & $\mathrm{Ni}$ & $\mathrm{Si}$ & $\mathrm{Mn}$ & $\mathrm{Nb}$ & $\mathrm{Fe}$ \\
\hline 1 & & 25.67 & 19.33 & 1.51 & 0.75 & 0.26 & 52.49 \\
$2,4,5,7$ & 4.08 & 26.91 & 17.96 & 1.49 & 1.34 & 4.10 & 44.11 \\
3 & 5.97 & 16.14 & 20.12 & 0.57 & 0.53 & 41.40 & 25.27 \\
\hline
\end{tabular}

The microstructure of the as-cast sample, as found by OM, consists of an austenitic matrix and coarse primary carbides. Primary carbides are separated and distributed in the form of a continuous network through dendritic austenitic grains, and the accumulation of coarse carbides in the form of isolated islands located within austenitic grains (Fig. 6.a). By quantitative EDS analysis, it was found that the first primary carbides were MC and $\mathrm{M}_{7} \mathrm{C}_{3}$.

The quantitative EDS analysis of the present microcontinents for the cast condition is given in Table 3. From Fig. 6 it can be observed that carbides are present in a different morphological form and appearance, i.e., the $\mathrm{M}_{7} \mathrm{C}_{3}$ carbides are black and $\mathrm{MC}$ white. It has been found that the content of chromium in carbides is variable and ranges from $16 \%$ to $27 \%$. In the as-cast sample, Fig. 6 (a), a dendritic carbide network with carbide chains, islands of coarse carbides inside the grain, and the grain boundaries may be seen in the austenitic matrix. The carbide network is more pronounced due to the slow cooling rate of casting with the thicker walls. During cooling of the castings in the process of crystallization (especially slower), there is a decrease in the solubility of carbon in austenite, when during cooling the crystallization front pushes ahead carbon initiating the formation of carbide in the form of a dendritic carbide network. 


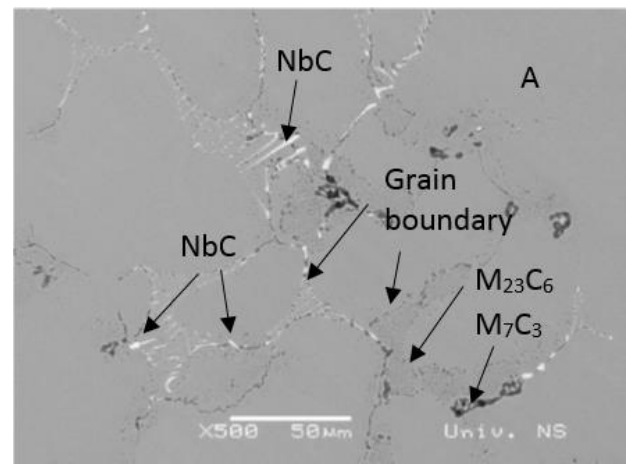

$a$.

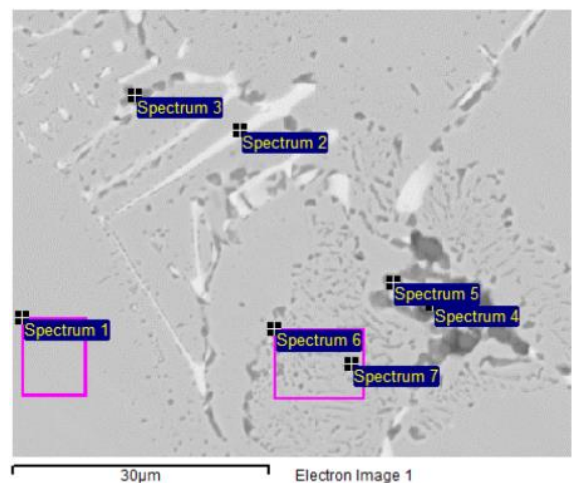

b.

Fig.7.SEM analysis of the microstructure of the solution annealed sample (a) at low magnification; (b) at higher magnification with marked positions for quantitative EDS analysis.

Table 4. Quantitative EDS analysis for the solution annealed sample, at the locations indicated in Fig. 7.b.

\begin{tabular}{lccccccc}
\hline \multirow{2}{*}{ Spectrum } & \multicolumn{7}{c}{ Composition, wt. \% } \\
& $\mathrm{C}$ & $\mathrm{Cr}$ & $\mathrm{Ni}$ & $\mathrm{Si}$ & $\mathrm{Mn}$ & $\mathrm{Nb}$ & $\mathrm{Fe}$ \\
\hline 1 & & 25.79 & 19.62 & 1.51 & 1.21 & 0.56 & 51.31 \\
2 & 13.36 & 5.68 & 0.97 & & 0.29 & 76.20 & 3.52 \\
$3,5,6,7$ & 7.32 & 28.52 & 16.81 & 1.41 & 1.64 & 0.51 & 43.79 \\
\hline
\end{tabular}

Solution annealing aims to break down the coarse dendritic network of primarily formed carbides. This allows the transfer of a part of the primary carbide into a solid austenitic solution, and the slow cooling allows the partial transformation of the primary, and possibly the extraction of the secondary carbide phase to a lesser extent. Microstructural studies showed apparent differences between the microstructure the ascast and solution annealing conditions, primarily in the carbide phase morphology (see Fig. 6 and 7). It is noted that in the process of dissolution the carbide chain distributed along the boundaries of austenitic grains was broken, whereas the size of carbides was reduced. By quantitative point EDS analysis, it was found that after the dissolution the content of chromium was increased around carbide particles. This can be explained by the dissolution of carbides and chromiumdifussion under the influence of high temperature, which results in an increase in the chromium content around carbides. Also, in the vicinity of massive carbides, the presence of small or broken carbides is observed, which is probably due to the dissolution of massive lamellar carbides at the grain boundaries. In the microstructure of the as-cast sample, these carbides were not detected, which confirmed the effect of solution annealing on the transformation of the microstructure through the change in the morphology of the carbide phase (Fig.7. a). 


\section{Conclusion}

The effect of high-temperature solution annealing of heat resistant $\mathrm{HK} 30 \mathrm{Nb}$ steel casting on microstructure and mechanical properties was studied by optical and scanning electron microscopy, hardness and room temperature tensile test.

Hardness and tensile properties of samples after the solution annealing have a slightly lower values than the as-cast samples, which is probably the result of the dissolution of primary carbides present in the initial as-cast condition.

Values of tensile properties of both conditions are higher than prescribed by standards.

\section{References}

[1] ASM Handbook: Properties and Selection: Irons, Steels, and High-Performance Alloys, Volume 1, (Cast Stainless Steels, Revised by Malcolm Blair), 1990, p.2195

[2] Handbook, Steel Castings. "Supplement 9. High Alloy Data Sheets. Heat Series." Ohio: Steel Founder's Society of America (2004) p. 28.

[3] B. Piekarski, J. Kubicki: Arch Foundry Eng, 8 (2008) 115-120.

[4] George E. Totten, STEEL HEAT TREATMENT HANDBOOK, Second Edition, Portland, Oregon, U.S.A., 2004, p.718

[5] F. Silva, J. Santos, R. Gouveia: Metals, 7 (2017): 251.

[6] Designation: A 351/A 351M - 03, Standard Specification for Castings, Austenitic, Austenitic-Ferritic (Duplex), for Pressure-Containing Parts, ASTM International, 2003, p.3

[7] Standard BAS EN ISO 6892-2: 2012

[8] EUROPEAN STANDARD EN 10295:" Heat resistant steel casting", October 2002, p. 10

[9] Honeywell, IDM standard 8365: "CAST HEAT RESISTANT Nb MODIFIED HK30 STAINLESS STEEL", 2012, p.4

[10] A.Delić: "Research of relations between the microstructure and the properties of the heat resistant austenitic steel HK30 modified by niobium in order to improve the properties at elevated temperatures", Doctoral dissertation, Faculty of Metallurgy and Technology, University of Zenica, 2018, 64-88.

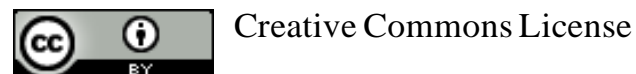

This work is licensed under a Creative Commons Attribution 4.0 International License. 